Universidad de Lima

Facultad de Comunicación

Carrera de Comunicación

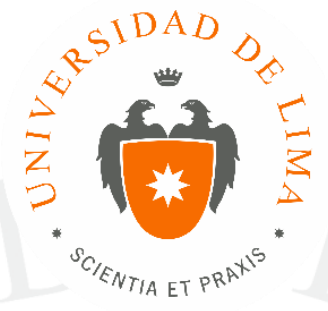

\title{
CAMBIO DE HORA
}

Trabajo de Suficiencia Profesional para optar el Título Profesional de Licenciado en Comunicación

\section{GEAN POOL UCEDA ESPINOZA}

Código 19951171

$$
\text { Lima - Perú }
$$

18 de septiembre de 2018 
CAMBIO DE HORA 


\section{PRÓLOGO}

“Los dramas adultos atraviesan una crisis ideológica, están obsesionados con el crimen y la historia, respuestas típicas

a la era en la que estamos. En los dramas juveniles

es donde se están produciendo las conversaciones

más interesantes sobre

nuestra sociedad"

Bryan Elsley.

Dramaturgo y escritor de series como Skins, Nature Boy. 


\section{ÍNDICE}

TÍTULO DEL PROYECTO …...................................................... 2

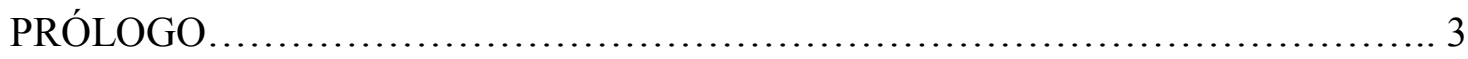

ÍNDICE

4

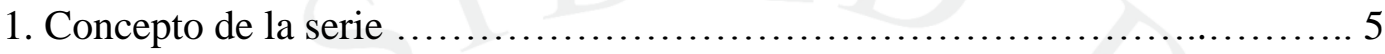

2. Sustentación

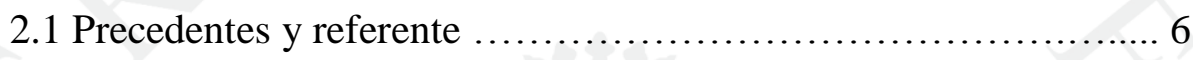

2.2 Genero, público y tema............................................. 7

2.3 Ángulo diferencial y posicionamiento.......................... 8

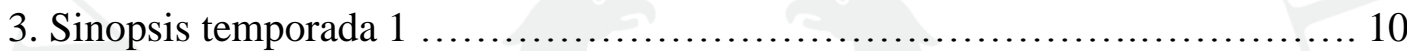

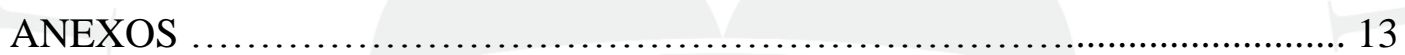




\section{Concepto de la serie}

Cambio de hora, es una serie web, que nos cuenta como un grupo de alumnos de un colegio han decidido hacer frente a las decisiones radicales de una nueva directora, que ha cesado casi todas las actividades extracurriculares del colegio.

Planifican su accionar sin que nadie se dé cuenta, utilizando los cinco minutos de tiempo de sus cambios de hora.

Es así como deciden emprender una arriesgada acción tomando el auditorio del colegio dentro de una asamblea planteada por la nueva dirección, donde se dictarán las nuevas normas del colegio. 


\section{Sustentación}

\subsection{Precedentes y referentes.}

Dada la peculiaridad del tema, Cambio de Hora, se presenta como una serie nueva que retrata una situación muy peculiar dentro de este colegio secundario. Está inspirada en distintas series: Señorita Maestra, Carmín, Cero en Conducta, Al salir de Clase, Carrusel, Los años maravillosos, Compañeros, Rebelde Wey, RBD, America Kids, Un Paso Adelante, Glee.

Sin embargo, la idea primaria está basada en tres creaciones:

\section{Cambio de Hora}

Obra de teatro de la compañía Yuyachkani Perú 1998. Comedia de distintas situaciones donde todo se refleja dentro de los cambios de hora en un colegio fiscal.

De esta obra, obtuve el nombre y el espíritu combativo de los personajes.

\section{Merlí}

TV3 España 2015. Idioma Catalán. Serie española ambientada en un instituto de bachillerato.

Con 40 capítulos distribuidos en 3 temporadas, la serie protagonizada por Francesc Orella, congregó ante la pequeña pantalla a 530.000 telespectadores promedio y un $18,5 \%$ de share, situándose a mucha distancia de las otras dos series de prime time, en Catalunya.

\section{Física o Química}

España 2008. Idioma Español. Serie ambientada en una escuela secundaria. Tuvo 7 temporadas ininterrumpidas entre 2008 y 2011 con una audiencia media de 2649000 lo cual representó un 15,5\% del share. De estas dos series, rescaté el que siempre intenten tocar temas importantes que son relevantes para los adolescentes y para los adultos tal vez no. 
2.2. Género, público y tema.

En su época, lo tenían más fácil por tener adversarios más definidos: Hitler y Stalin. Sin embargo, «... los jóvenes de ahora se juegan la libertad y los valores más importantes de la humanidad»

Stéphane Hessel.

Es un drama adolescente con tintes de comedia, dirigido a jóvenes y niños en edad escolar y preuniversitarios, consumidores por excelencia de plataformas cada vez más convencionales.

Nuestro core target, está comprendido por jóvenes escolares o pre universitarios, entre 13 y 16 años.

Nuestra estrategia de difusión será a través de las distintas plataformas con distintos contenidos vinculados a nuestra serie web, logrando hacer de este un producto transmedia. La plataforma troncal por la que proponemos se emita nuestra serie es Youtube, debido a su gran uso por parte de nuestro público objetivo. La sugerencia de emisión es los días viernes a las 15:00, horario de salida de casi todos los escolares.

2.3. Ángulo diferencial y posicionamiento.

El 29 de enero de este año, el estudio de We are Social \& HootSuite, indicó que solo en el Perú, tenemos cerca de 22 millones de usuarios de internet sobre los 32.3 millones de pobladores peruanos.

Y dentro de esta estadística, encontramos a cerca de 1.5 millones de espectadores ente los 13 y 18 años que son heavy users, de Facebook y Youtube, haciendo de este, un mercado bastante atractivo para su explotación.

El valor diferencial de nuestra serie es el grado de empatía que se generaría entre los espectadores y los interpretes de la serie. Jóvenes de la misma edad, óptica y visión, contando cómo se enfrentan con una solución poco común ante un problema tal vez maximizado pero que puede ser real, como es la poca aceptación de imposiciones de parte de adultos hacia jóvenes. 
Todos los textos usados dentro del guión han sido adaptados según propia iniciativa de los mismos actores, usando un lenguaje juvenil, universal y libre de groserías.

Todas las situaciones giran alrededor de un hecho que sucederá durante toda la temporada que es "tomar el control del colegio", pero no es lo único que sucede, ya que las distintas líneas dramáticas crean un tejido de realidad, que a pesar de que también confluyen en la misma línea, nos hace identificarnos, siendo esta, una clave clara, para hacer atractivo un producto audiovisual.

3. Sinopsis Temporada 1

\section{ler capítulo}

\section{El primer cambio de hora}

“... Un grupo de alumnos viene planificando una huelga dentro del colegio. Ante esto, y presas de temores, algunos alumnos del grupo de debate liderados por José, intentan frenar la huelga. Los del grupo de teatro liderados por Estefanía y que secundan la huelga, plantean una votación. José plantea una salida diplomática, Estefanía, quiere hacer una huelga y tomar el colegio, frente a lo que ellos consideran abusos por parte la dirección.

Se genera un evidente malestar entre Estefanía y José, luego de la votación en la que gana el No a la huelga, gracias a la pérdida de votos por miedo a represalias por parte del colegio. La aparición de la directora Rangel cortará toda la situación..."

\section{2do capítulo}

\section{La primera represalia}

La salida diplomática no surte efecto y debaten nuevamente. Casi por unanimidad deciden que harán huelga. Estefanía consuela a José, ante la atenta mirada del grupo. Lolo, se muestra cada vez más curioso y hace muchas preguntas. La nueva dirección de estudios decide prohibir las reuniones internas dentro del colegio, alguien está filtrando información a dirección, quienes se valen de las cámaras de seguridad para sospechar.

\section{3er capítulo}

\section{El primer consenso}

No todos están de acuerdo con las decisiones que se vienen tomando. Se ha creado una pugna por el poder, aparece un nuevo grupo que también está en contra de los cambios, los deportistas, pero están divididos. Lo que genera que 
la participación total de los alumnos del colegio, corra riesgo. Estefanía logrará solucionar todo el problema ya que conoce a Joaquín capitán del equipo de Basket, desatando los celos de José.

\section{4to capítulo \\ El primer plan}

Luego del consenso entre todas las fuerzas del colegio, los estudiantes deciden poner fecha y lugar para la huelga. José y Estefanía discuten, ya que no se ponen de acuerdo en el momento adecuado para la huelga, Lolo pone orden y todos obedecen. Desde la dirección, se filtra información que iba a ir en contra de los planes de la huelga, alguien de la dirección está a favor de la manifestación de los estudiantes. Los alumnos cambian los planes de acuerdo a la información que recibieron.

\section{5to capítulo \\ El primer intento}

Se ha acordado que sea el primer recreo el momento en el que se lleve a cabo el plan para ir a la huelga. Repentinamente la dirección decide suspender el recreo y reunir a todos los alumnos en el auditorio general. José y Estefanía intentan hacer que nadie llegue hasta el auditorio, pero no lo pueden evitar. Lolo, una vez más asume la voz de mando en el auditorio. Algunos alumnos del grupo de teatro sorprenden a todos con una increíble iniciativa.

\section{6to capítulo}

\section{La primera toma}

Luego de una manifestación espontánea por parte de un grupo de alumnos del grupo de teatro, varios alumnos deciden trancar las puertas del auditorio antes de que llegue el consejo de dirección. Se respira tensión en el auditorio y los alrededores del colegio. Estefanía y Lolo intentan moderar la toma del auditorio, mientras Josema se muestra reacio por una manifestación así. Llegan a la conclusión de que todos son Fuenteovejuna, todos a una. José y Estefanía se vuelven los líderes de la toma auditorio, se da un cierto flechazo entre los dos.

\section{7 mo capítulo}

\section{La primera negociación}

Gracias a la iniciativa de José, los alumnos han decidido dejar salir a los pocos profesores que se encontraban. Comienzan los problemas dentro del auditorio cuando surgen los deseos de usar los baños y conseguir alimentos. Lolo, tiene muchas ganas de ir al baño, se orina en los pantalones, mientras que los otros alumnos se burlan de él. Estefanía tiene una solución un poco ortodoxa. Ante el recrudecimiento de las medidas que impone la dirección, la presencia de 
una nueva fuerza surge en el colegio., los padres de familia. Los estudiantes amenazan con filtrar información a la prensa. José y Estefanía coquetean.

\section{8vo capítulo}

\section{La primera victoria}

La aparición de la presidenta de los padres de familia evita que la huelga llegue a una situación insostenible. Los alumnos liderados por José y Estefanía han accedido a comida y aseos a cambio de conversar con la dirección y desistir de convocar a la prensa. Ha llegado el momento de tomar decisiones entre los alumnos para poner o no fin a la manifestación. La conversación entre la dirección, padres de familia, se da frente a todos los alumnos del colegio, en una gran asamblea a puerta cerrada. 


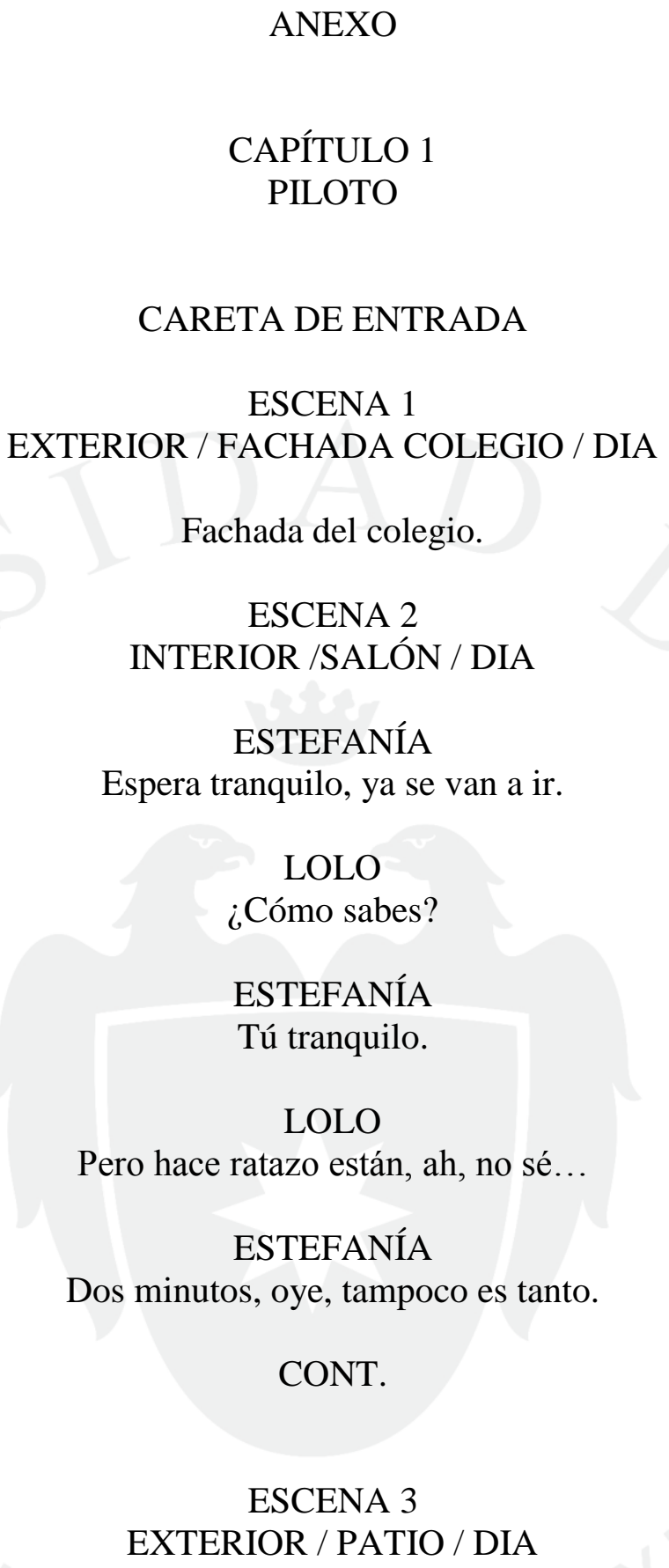

Dos profesores conversan, una tercera se acerca, los vemos irse.

CONT.

ESCENA 4

INTERIOR /SALÓN / DIA

Lolo y Estefanía mira por la ventana, voltean. Dentro del salón hay más personas.

Estefanía

Ves. 
Lolo

Ala

Se ríen.

Juan

¿Ya está subiendo?

Lolo

Sí.

Estefanía

¿Bueno, empezamos entonces?

Juan

Esperemos a José.

Estefanía

Pero está subiendo.

Entra José.

Estefanía

¿Ahora sí, ya estás contento?

José

Bueno, empecemos de una vez.

Luna

Quiero ir al baño.

Adri

¿Estamos seguros que 8vo va a venir? No hay nadie de esos salones y nos quedan solo 4 minutos hasta que entre Arturo.

Estefanía

(Aclarando) Profesor Arturo, ya no podemos ni llamarlo por su nombre.

Juan

Nos tenemos que apurar.

Adri

Faltan los Verastegui.

José

Bueno, ¿entonces? Tenemos que votar.

Adri

Solo un minuto, esperemos a que llegue alguien de 8 vo. 
Estefanía

Y los Verastegui.

Juan

No podemos esperar más.

Luna

Me hago la pichi.

Estefanía

Te aguantas un rato.

Juan

Ya pasó un minuto.

\section{Estefanía}

No es justo que tengamos que tomar una decisión cuando no estamos todos completos.

Llegan Alonso y María.

Estefanía

Ya, ahora sí, votemos.

Adri

Pero los Verastegui...

\section{Estefanía}

(Susurrando) ya no importa, ya tenemos los votos...

Luna

Necesito ir al baño.

José

Corre de una vez, que no te vea nadie.

Estefanía

Tenemos que apurarnos.

Adri a Alonso y Maria

Adri (Susurrando)

Ya era hora, dónde se habían metido.

Maria (Susurrando)

Pérez no nos dejaba salir.

Alonso (Susurrando)

Creo que se las huelen. 
Lolo mirando a la ventana.

Lolo

Están volviendo.

CONT.

ESCENA 5

EXTERIOR / PATIO / DIA

Los profesores vuelven a su posición inicial, con cafés en las manos.

CONT.

ESCENA 6

INTERIOR / SALÓN / DIA

Miradas de Maria y Alonso. Algunos van a ver la ventana. José desde donde está sentado.

José

Entonces, ¿Quién está a favor de dialogar y buscar una solución pacífica?

La mayoría levanta la mano, entre ellos Maria y Alonso.

Estefanía, Lolo y Adri se sorprenden.

Estefanía

¿No se supone que apoyaban la huelga?

María

Pucha Stef, me da miedo, mi papá me mata si se entera que estoy metida en una huelga.

Alonso

Yo ni lo pienso, estoy malazo en mate y science, estoy fregado.

Estefanía

Fregados estamos todos, no nos van a dejar hacer nada. Necesitamos hacer esa huelga, tenemos que hacer valer nuestros derechos.

Adri

Luego hablamos (A Maria y Alonso)

José

Bueno, creo que está claro que nadie quiere una huelga. 


\section{Estefanía}

No entiendo, ¿no se han dado cuenta de lo que está pasando? Rangel nos odia, con las reformas que está haciendo, todos hemos dejado de hacer las cosas que nos gustan.

Adri

Nadie quiere problemas, pero tenemos que hacer algo para defendernos.

Estefanía

¿Nos han quitado talleres y elencos, ustedes creen que Rangel quiera dialogar?

Juan

Todo se arregla hablando.

Estefanía

Este no es el círculo de debate, y obviamente sabemos que ese grupo también va ser cerrado. ¿No se dan cuenta?

Adri

Nos tienen amenazados

José

Yo estoy seguro que nadie quiere exponerse a repetir año, o que llamen a sus papás.

Rangel se está pasando con un montón de medidas abusivas, pero se puede hablar, siempre se puede hablar.

Estefanía

No seas iluso.

María

No es tan fácil Stef, no puedo repetir año...

Barullo todos hablan.

Lolo

Shhhh silencio, no hagan tanta bulla...

PAUSA.

CONT

ESCENA 7

EXTERIOR / PATIO / DIA

Los profesores miran a la ventana.

CONT. 


\section{ESCENA 8 \\ INTERIOR / SALÓN / DIA}

Lolo

Están mirando para acá.

José

Tenemos que votar de una vez... ¿quienes votan por ir a hablar con Rangel y no hacer huelga?

Cuando están por votar, aparecen los Verástegui.

Adri

Ya era hora...

\section{Ursula V}

Es que llegamos tarde...

Adri

Viven al lado del colegio.

\section{Juan V}

Se demora dos horas en el baño...

Pequeño gesto de victoria de Estefanía...

\section{Juan}

Bueno, a votar entonces, ¿quiénes dicen no a la huelga?

Levantan la mano casi todos, solo Estefanía, Adri y Lolo no levantan la mano, pero al final Lolo, no puede evitarlo y levanta la mano.

Estefanía
¿Tu??
Adri
Lolo...

José

Entonces, no a la huelga, vamos saliendo, rápido... quedamos en el siguiente cambio de hora...

Todos están por salir rápidamente.

Lolo

No quiero repetir año Stef. No sabía que podía repetir año si hacía huelga.

Estefanía

No... es no es así... ya hemos hablado de esto... 
Jimena entra corriendo con Lucas...

Lucas

Rangel...

Luna

Viene para acá...

Todos se acercan a la ventana.

\section{CONT.}

ESCENA 9

EXTERIOR / PATIO / DIA

Vemos a la Directora Rangel mirando hacia la ventana, se detiene desafiante y los mira, mientras camina hacia el salón de clases y todo el salón se alborota. Timbre de cambio de hora. 